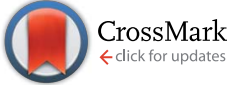

Cite this: Chem. Sci., 2016, 7, 5581

\title{
Nickel-catalyzed C-3 direct arylation of pyridinium ions for the synthesis of 1-azafluorenes $\dagger$
}

\author{
Jean-Nicolas Desrosiers, ${ }^{\star a}$ Xudong Wei, ${ }^{* a}$ Osvaldo Gutierrez, ${ }^{b}$ Jolaine Savoie, ${ }^{a}$ \\ Bo Qu, ${ }^{a}$ Xingzhong Zeng, ${ }^{a}$ Heewon Lee, ${ }^{a}$ Nelu Grinberg, ${ }^{a}$ Nizar Haddad, ${ }^{a}$ \\ Nathan K. Yee, ${ }^{a}$ Frank Roschangar, ${ }^{a}$ Jinhua J. Song, ${ }^{a}$ Marisa C. Kozlowski ${ }^{\star b}$ \\ and Chris H. Senanayake ${ }^{a}$
}

The direct arylation of pyridine substrates using non-precious catalysts is underdeveloped but highly desirable due to its efficiency to access important motifs while being extremely cost-effective. The first nickel-catalyzed C-3 direct arylation of pyridine derivatives to provide a new approach to valuable 1-azafluorene pharmacophore frameworks was developed. This transformation is accomplished using air-stable nickel catalyst precursors combined with phenanthroline ligands and tolerates a variety of substituents. Computational studies suggest facile oxidative addition via the pyridinium form, deprotonation, and a subsequent carbo-nickelation cyclization. Nickel homolysis/recombination permits isomerization to the stereochemical array needed for the final elimination.

Received 1st April 2016

Accepted 19th May 2016

DOI: $10.1039 / \mathrm{c} 6 \mathrm{sc} 01457 \mathrm{~g}$

www.rsc.org/chemicalscience

The direct arylation of pyridine derivatives is a highly efficient approach for the synthesis of various heteroaromatic building blocks. ${ }^{1}$ No pre-installment of a functional group on the pyridine core, such as a halogen or boron derivative, or stoichiometric metalating reagent is required to promote the arylation which translates into better step economy, cost-efficiency, as well as reduced waste. ${ }^{1,2}$ The possibility to achieve a pyridine direct arylation using a non-precious metal catalyst such as nickel is highly desirable since it is sustainable due to its natural abundance and its significant yearly production. ${ }^{3}$ Nickel is also inexpensive, potentially air-stable, and exhibits a distinctive reactivity. ${ }^{3}$

As a part of the Non-Precious Metal Consortium ${ }^{4}$ and the preparation of an active pharmaceutical ingredient, efforts were devoted toward the development of a sustainable synthesis of 1azafluorenes. These heterocycles are valuable pharmacophores that exhibit a wide range of biological activities. For instance, indenopyridines have demonstrated efficacy as thrombin inhibitors, for arresting tumor cell growth, and for the treatment of inflammatory and central nervous system related diseases. ${ }^{5}$ These heterocycles also possess absorption and emission properties, which are widely utilized for the development of dyes ${ }^{6}$ and light-emitting materials. ${ }^{7}$ In addition, the reduced form, indeno-hexahydro-pyridine, can be found in the

${ }^{a}$ Department of Chemical Development US, Boehringer-Ingelheim Pharmaceuticals, Inc., 900 Ridgebury Road, Ridgefield, CT, 06877, USA. E-mail: nick.desrosiers@ boehringer-ingelheim.com; xudong.wei@boehringer-ingelheim.com

${ }^{b}$ Department of Chemistry, University of Pennsylvania, Philadelphia, PA 19104-6323, USA. E-mail: marisa@sas.upenn.edu

$\dagger$ Electronic supplementary information (ESI) available. See DOI: $10.1039 / \mathrm{c} 6 s c 01457 \mathrm{~g}$ core of natural products such as haouamines that have potent anticancer activity. ${ }^{8}$ Given the versatility and numerous applications of 1-azafluorenes, it is surprising that little attention has been dedicated to the synthesis of these compounds. ${ }^{5,6,9}$ Herein, we describe the first nickel-catalyzed C-3 direct arylation of pyridine derivatives (Fig. 1) to provide a new approach to valuable 1-azafluorene pharmacophore frameworks. Computational studies and control experiments revealed key elements of the reaction pathway explaining the unprecedented reactivity of pyridinium ions.

Despite the numerous advantages of combining the effectiveness of a direct arylation with the cost-efficiency of nickel, ${ }^{10}$ there are relatively few examples of nickel-catalyzed direct arylation of pyridine derivatives. Notably, Chatani reported a C-2 selective $\mathrm{C}-\mathrm{H}$ bond arylation of pyridines and quinolines via a nickel-catalyzed 1,2-addition with diorganozinc reagents. ${ }^{11}$ More recently, Doyle et al. described the C-2 arylation via Ni(II) $\pi$-allyl intermediates of $N$-acyl pyridinium ions with either boronic acids ${ }^{12}$ or aryl zinc halide reagents. ${ }^{13}$ In spite of these precedents, until now, the corresponding nickel-catalyzed C-3 direct arylations of pyridine derivatives have not been reported. ${ }^{14,15}$

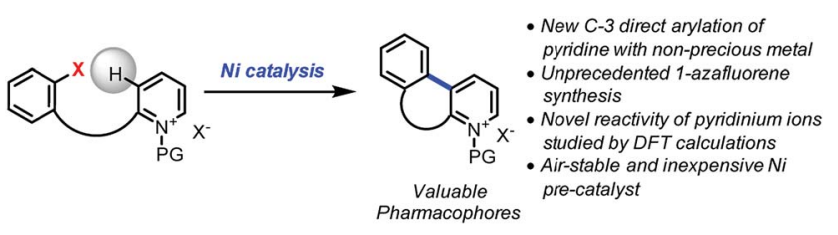

Fig. 1 Nickel-catalyzed C-3 direct arylation of pyridine derivatives. 
Notwithstanding the absence of reported methodology for C3 direct arylation of pyridines with nickel, ${ }^{16}$ we envisioned using this challenging approach as a general platform for the synthesis of 1-azafluorenes (Fig. 1). Even though substrate 1 seems poised for directed insertion to the C-3-position of pyridine after oxidative addition of the aryl- $\mathrm{X}$ group, initial experiments did not provide the desired 1-azafluorene product (Scheme 1). Reasoning that the nonaromatic dihydropyridine 2 could exploit an alternative carbo-metalation pathway, we were intrigued when it performed poorly under various reaction conditions during the optimization stage. Surprisingly, careful control studies revealed that the corresponding pyridinium ions 3 generated the 1-azafluorenes far more effectively. Mechanistic and computational studies revealed the source of the greater reactivity of the pyridinums providing useful design principles for future insertion-cyclization reactions.

Further reaction optimization of the pyridinium ion showed that the $N$-benzyl derived 4a was optimal due to the reactivity it induces, ease of substrate preparation, and ease of cleavage of the protecting group. Screening (Table 1) of air-stable nickel(II) sources, including $\mathrm{Ni}(\mathrm{acac})_{2}$, (TMEDA)NiTolCl, ${ }^{17}$ and $\mathrm{NiX}_{2}(\mathrm{X}=$ $\mathrm{Br}$ and $\mathrm{Cl})$, revealed that $\mathrm{NiCl}_{2}(\mathrm{dme})$ afforded superior yields with the use of $\mathrm{PPh}_{3}$ as ligand (entry 1-4). Further, bisphosphine and tridentate nitrogen ligands improved yields to 45 and $69 \%$, respectively (entry $5-7$ ). Inorganic bases including acetates and carbonates were not advantageous (entries 9-11).

Among all ligands tested in presence of DBU, phenanthroline derivatives were optimal (entry 12-18) with nickel(II) catalysts, and 1,10-phenanthroline gave rise to $98 \%$ yield (entry 12). Introduction of electron-donating, withdrawing or aromatic substituents on 1,10-phenanthroline did not enhance the rate or yield of the reaction.

With the optimized reaction conditions in hands, the substrate scope was surveyed (Scheme 2). Substitution with electron-withdrawing groups at C-6 such as esters (5b and $\mathbf{5 c}$ ), amides (5d), nitriles (5e) and sulfonamides (5f) was well tolerated $(77-95 \%)$. Notably, the aryl iodides underwent full conversion more rapidly (1-3 h) than the corresponding aryl bromides (8-12 h). 6,7-Difluoro and 7-methoxy substrates $\mathbf{5 g}$ and $\mathbf{5 h}$ provided the desired 1 -azafluorenes with moderate yields. Substitution of the pyridine ring (5i) at C-4 also was well tolerated. This method was found to be specific to azafluorenes

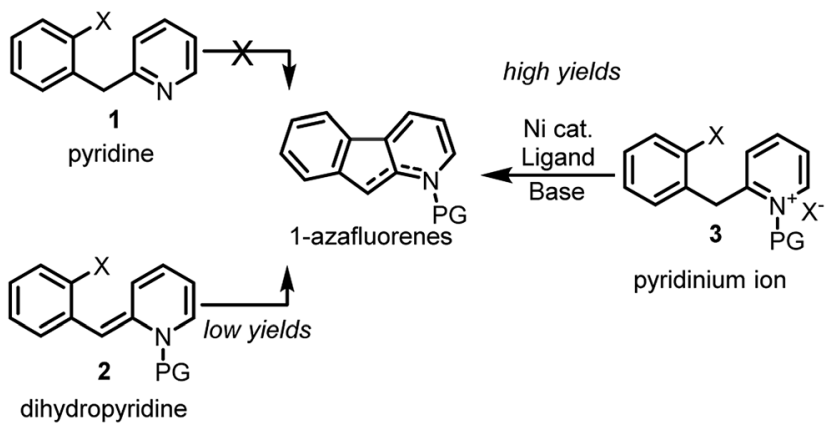

Scheme 1 Nickel-catalyzed C-3 direct arylation to generate 1azafluorenes.
Table 1 Optimization of direct arylation conditions ${ }^{a}$

\begin{tabular}{lllll}
\hline & & & \\
\end{tabular}

${ }^{a}$ Reaction conditions: Ni catalyst ( $5 \mathrm{~mol} \%$ ), ligand (6-12 mol\%), base (5.0 equiv.) in DMF at $120{ }^{\circ} \mathrm{C} .{ }^{b}$ HPLC assay \% yield determined by using a calibration curve. ${ }^{c}$ binap $=2,2^{\prime}$-bis(diphenyl-phosphino)-1, $1^{\prime}$ binapthalene. ${ }^{d} i$ Pr-pybox $=2,6$-bis[isopropyl-2-oxazolin-2-yl]pyridine.

since a longer tether did not afford the fused 6-membered ring $5 \mathbf{j}$ with high efficiency.

The usefulness of cyclized $N$-benzyl derivatives 5 was established by performing a straightforward deprotection to afford the corresponding 1-azafluorene 6 or the indeno-hexahydropyridine 7 (Scheme 3). Specifically, hydrogenolysis of the benzyl protecting group under a low pressure of hydrogen (100 psi) at room temperature with $\mathrm{Pd} / \mathrm{C}$ provided 6 in $91 \%$ isolated yield. At higher hydrogen pressure and temperature, reduction of the pyridine ring can also be accomplished to furnish cis-fused piperidine 7 in $82 \%$ yield.

In terms of the mechanism, various pathways are reported to achieve a direct arylation and several possibilities were considered including concerted deprotonative metalation, $\mathrm{Ni}(\mathrm{I})$ or Ni(II) single electron abstraction of the halide to initiate a radical sequence, and carbo-metalation process. As acid sources are present, the protonation state (pyridinium ion or dihydropyridine) was also evaluated.

DFT studies were initiated using bipyridine as ligand and the neutral version of $N$-methyl 2-(2-bromobenzyl)pyridine as a model substrate. ${ }^{18,19}$ Fig. 2 illustrates several of the pathways identified. ${ }^{20}$ Ligand dissociation (COD) followed by coordination of the $\mathrm{Ni}(0)$ to the aryl ring of the dihydropyridine generates 


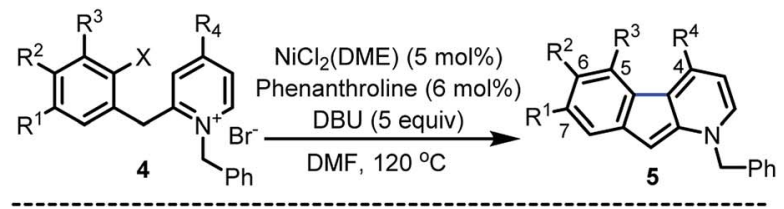

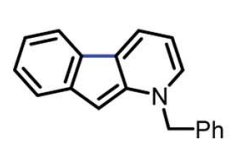

5a, $\mathrm{X}=\mathrm{Br}$ $92 \%$ yield

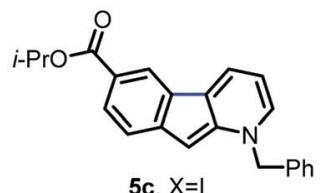

$94 \%$ yield

NC,

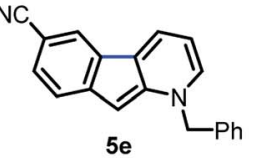

$\mathrm{X}=\mathrm{Br}: 77 \%$ yield $X=I: 80 \%$ yield
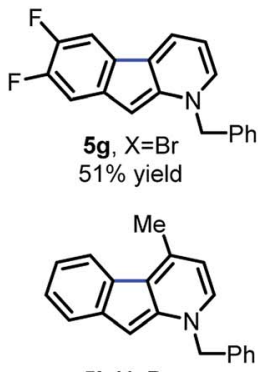

5i, $\mathrm{X}=\mathrm{Br}$

$75 \%$ yield
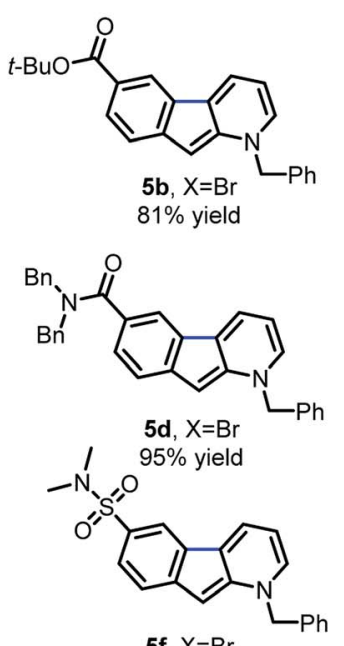

5f, $\mathrm{X}=\mathrm{Br}$ $95 \%$ yield

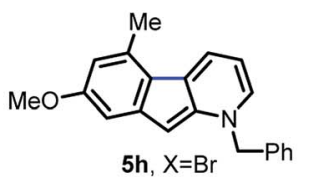

$48 \%$ yield

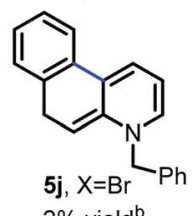

Scheme 2 Reaction scope of C-3 arylation of pyridinium ions ${ }^{a}$. ${ }^{a}$ Reaction conditions: $\mathrm{Ni}$ catalyst (5 mol\%), 1,10-phenanthroline (6 mol\%), DBU (5.0 equiv.) in DMF at $120{ }^{\circ} \mathrm{C}$ for $1-12 \mathrm{~h}$; isolated yield determined after flash chromatography. ${ }^{b}$ Determined by ${ }^{1} \mathrm{H}$ NMR assay yield using dimethyl fumarate as an internal standard.

adduct $\mathbf{A}$, which is subject to two distinct fates. An energetically accessible oxidative addition (barrier $=20.3 \mathrm{kcal} \mathrm{mol}^{-1}$ from uncoordinated substrates) via A-TS (blue pathway) leads to the much more thermodynamically favorable $\mathrm{Ni}(\mathrm{II})$ adduct B. $^{21}$ Deprotonative metalation pathways have been reported in related systems, ${ }^{22}$ and transition states were located for the bromide-(B'-TS-Br, shown) or base-mediated (not shown, see ESI $\dagger$ ) deprotonation from B. However, all deprotonative metalation pathways were substantially higher in energy $(>12.2 \mathrm{kcal}$ $\left.\mathrm{mol}^{-1}\right)$ relative to migratory insertion via B-TS $\left(5.4 \mathrm{kcal} \mathrm{mol}^{-1}\right)$ which gives rise to the $\mathbf{C}$-anti adduct (see $\mathbf{E S I} \dagger$ for energetics of the deprotonative metalation pathway). However, the lack of a hydrogen syn to the Ni center in C-anti disfavors $\beta$-hydride elimination to form the product from this species.

These results together with the finding that 1-chloro-2,4dinitrobenzene, a single electron transfer inhibitor, ${ }^{23}$ was deleterious to the reaction, ${ }^{24}$ motivated us to examine single

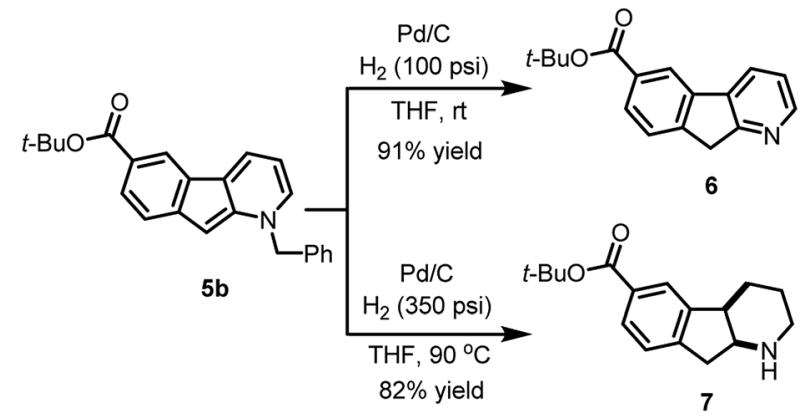

Scheme 3 Deprotection and hydrogenation of protected 1azafluorene.

electron transfer pathways. From a different coordination complex $\left(\mathbf{A}^{\prime}\right)$, halide abstraction by the $\mathrm{Ni}(0)$ (via $\mathbf{A}^{\prime}$-TS) was found to be higher in energy (1-5 $\mathrm{kcal} \mathrm{mol}^{-1}$ ) relative to oxidative addition (A-TS) depending on the method used (see ESI $\dagger$ ). On the other hand, halide abstraction commencing with $\mathrm{Ni}(\mathrm{I})^{25}$ was found to be much higher in energy and hence not viable (see ESI $\dagger$ ). At this juncture, distinction of the $\mathrm{Ni}(0)$ oxidative addition $v s$. halide abstraction was not obvious from the calculations alone. In addition, neither of these pathways satisfactorily explained the requirement of a proton source: either the pyridinium substrate needs to be employed or $\mathrm{DBU} \cdot \mathrm{HBr}$ needs to be introduced to the neutral dihydropyridine. ${ }^{26}$

On this basis, further modeling was undertaken starting with the cationic (pyridinium) version of the substrate (Fig. 3). Notably, oxidative addition $\left(\mathbf{A}^{2}\right.$-TS, $\left.13.5 \mathrm{kcal} \mathrm{mol}^{-1}\right)$ was found to be far more facile than halide abstraction $\left(\mathbf{A}^{\prime \prime}-\mathbf{T S},>38 \mathrm{kcal}\right.$ mol $^{-1}$, not shown, see ESI $\dagger$ ) when the charged species is considered. Furthermore, oxidative addition of the charged substrate is more facile than oxidative addition of the neutral analog (13.5 vs. $\left.20.3 \mathrm{kcal} \mathrm{mol}^{-1}\right)$. It appears that several effects give rise to this behavior. The neutral dihydropyridine is planar as a result of conjugation, but this conjugation is disrupted in A-TS due to steric interactions with the catalyst during oxidation addition. In contrast, the pyridinium is not conjugated and is not planar in its starting form; as a result, much less strain builds up in $\mathbf{A}^{2}$-TS (see ESI $\dagger$ for structures). Thus, the oxidative addition step is favored via the protonated pyridinium form, and then a facile deprotonation occurs, so that intramolecular migratory insertion can occur via the lower energy pathway B-TS (Fig. 2). Migratory insertion on cationic oxidative addition adduct $\mathbf{B}^{\prime}$ in Fig. 3 causes a loss of aromaticity in the pyridinium ring and is precluded energetically (transition state barrier from $\mathrm{B}^{\prime}$ is $49.6 \mathrm{kcal} \mathrm{mol}^{-1}$; not shown, see ESI†) vs. migratory insertion of neutral oxidative addition adduct $\mathbf{B}\left(31.1 \mathrm{kcal} \mathrm{mol}^{-1}\right.$ via B-TS in Fig. 2).

The remaining issue to resolve is how C-anti can undergo $\beta$-hydride elimination to the product. Due to the highly conjugated nature of the radical produced, calculations show that homolysis of the Ni-C bond of C-anti is facile leading to B1 (Fig. 2). Isomerization and recombination leads to C-syn, which can, in turn, undergo low barrier $\beta$-hydride elimination (via 


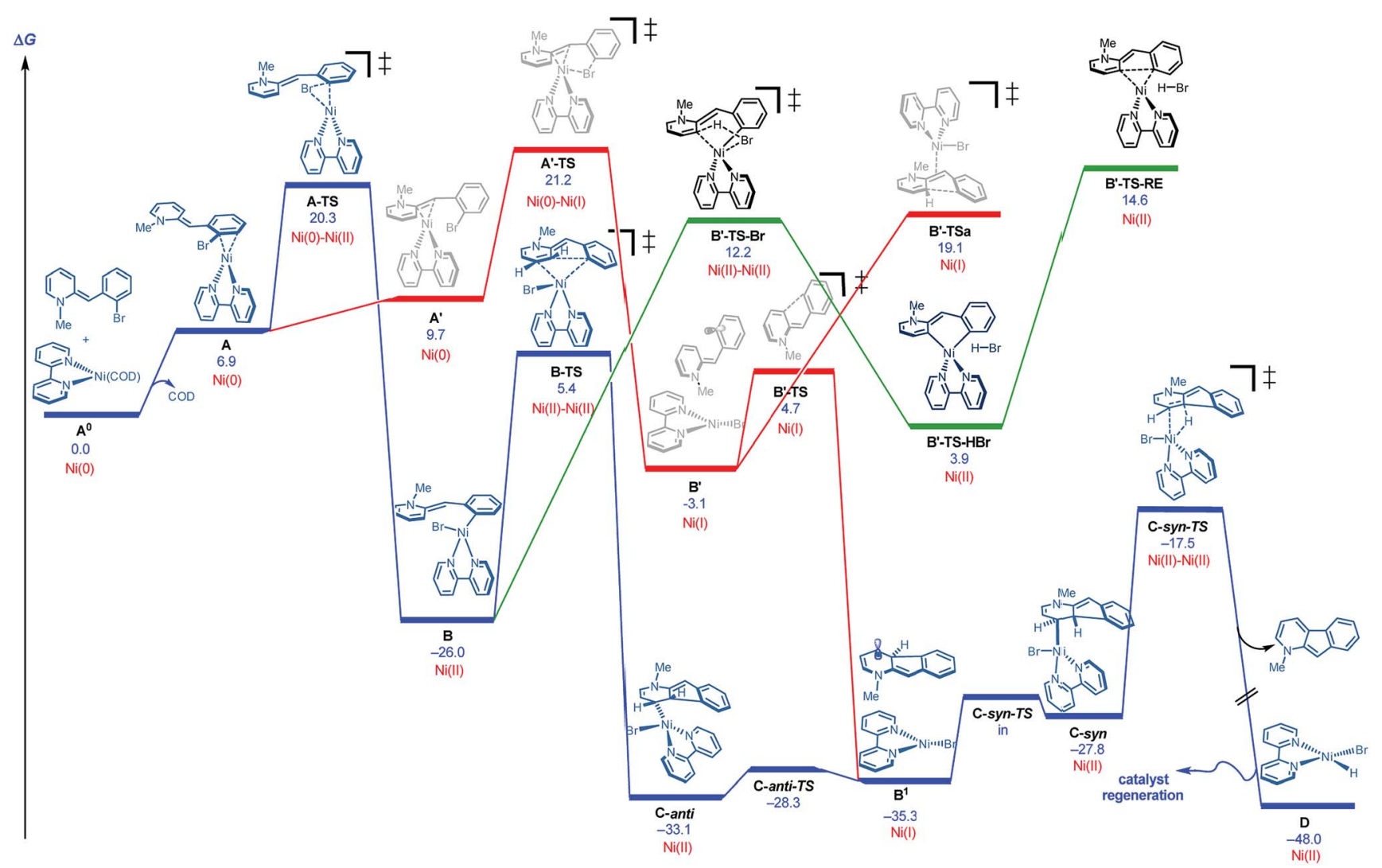

Fig. 2 Cyclization pathways commencing from neutral dihydripyridine (free energies are given in kcal mol ${ }^{-1}$ for calculations with UM06/6$311+G(d, p)-S M D-$ nitromethane//UB3LYP/6-31G(d)-gas).

C-syn-TS) to the product. This result also accounts for why an electron transfer inhibitor is deleterious. ${ }^{23}$

Overall, a carbo-nickelation accounts for the observed direct arylation products (Scheme 4). A notable feature is that substrate protonation distorts conjugation of the substrate positioning the requisite $\mathrm{C}-\mathrm{Br}$ in a less sterically encumbered environment which facilitates oxidative addition. Subsequent deprotonation is required for migratory insertion. The ability of nickel to undergo facile homolysis provides a low energy pathway for a cis to trans isomerization, which is needed for $\beta$-hydride elimination to product. Reduction of the Ni(II) precatalyst and of the $\mathrm{Ni}$ (II) hydride species could occur at $120{ }^{\circ} \mathrm{C}$ via either oxidation of $\mathrm{DBU}^{27}$ or oxidative decomposition of DMF. ${ }^{28}$ An alternative pathway for nickel reduction could be a redox process between $\mathrm{Ni}$ (II) and phenanthroline to generate $\mathrm{Ni}(\mathrm{I})^{19 a}$ which can then react with the aryl bromide to afford $\mathbf{B}^{2}$ after a bimetallic oxidative addition. ${ }^{29}$

In conclusion, an unprecedented C-3 direct arylation of pyridinium ions was developed using air-stable nickel catalyst precursors to achieve a practical synthesis of 1-azafluorenes. This strategy is compatible with a variety of substituents either on the aryl halide or pyridine core. The $N$-benzyl protected 1-azafluorenes readily undergo hydrogenolysis and reduction to afford valuable pharmacophores. This method represents a significant advance in non-precious metal catalysis considering that prior methods only permit C-2 direct arylation. Computational studies combined with control experiments

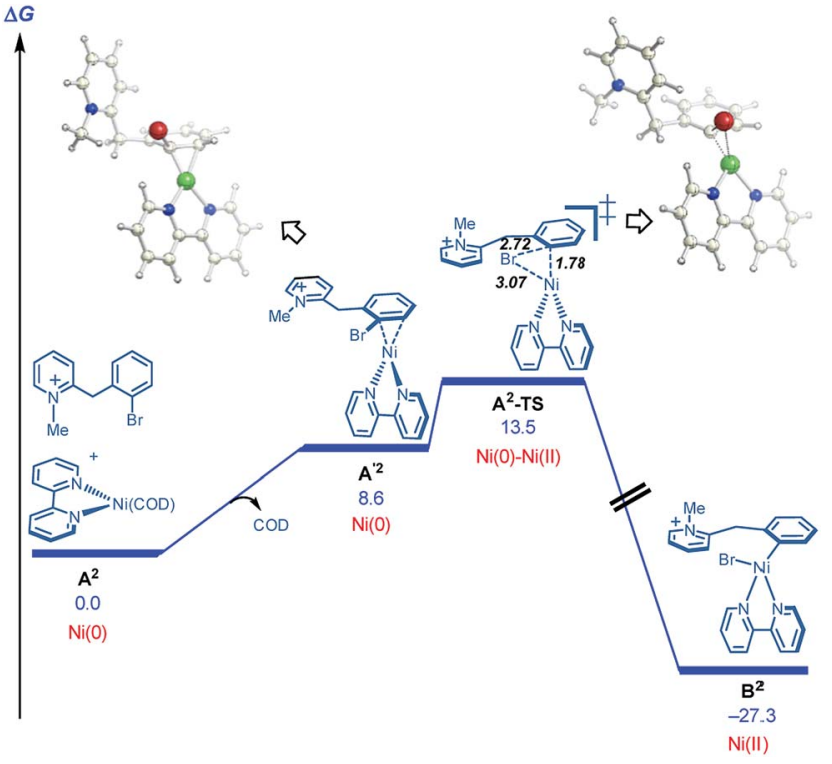

Fig. 3 Cyclization pathways commencing from the pyridinium ion ${ }^{a}$. ${ }^{a}$ Free energies are given in $\mathrm{kcal} \mathrm{mol}^{-1}$ for calculations with UM06/6$311+G(d, p)-S M D-$ nitromethane//UB3LYP/6-31G(d)-gas phase.

revealed that the oxidation addition step is sensitive to steric hindrance which can be mitigated by use of the pyridinium ion. The subsequent cyclization takes place only after isomerization 


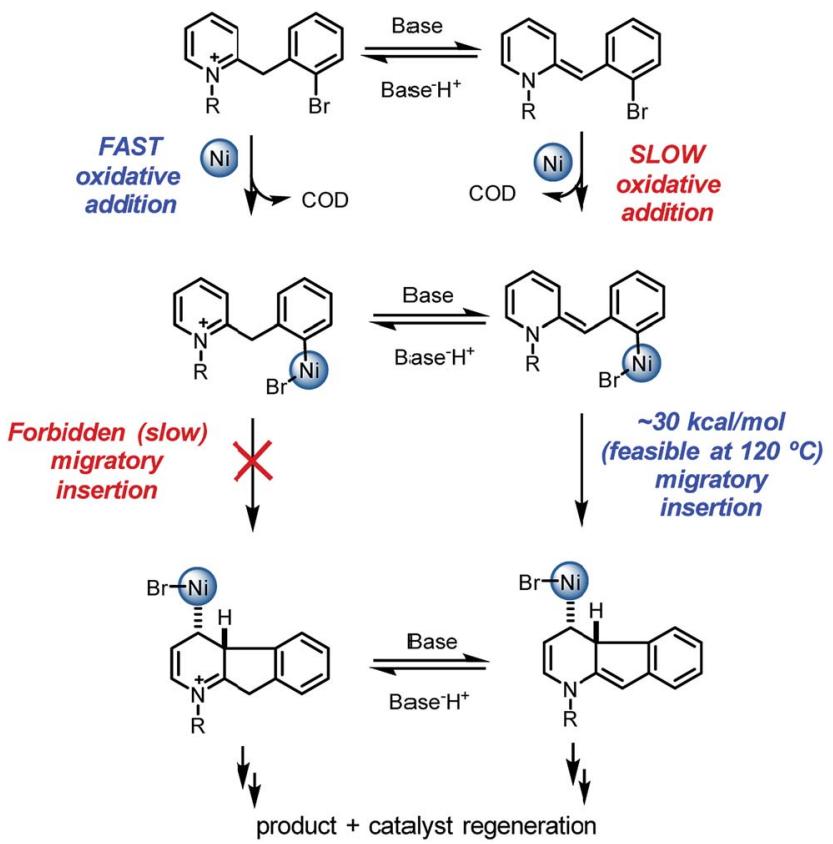

Scheme 4 Overall mechanism of the pyridinium direct arylation.

under basic conditions. Finally, the homolysis/recombination provides the required configuration for $\beta$-hydride elimination. These mechanistic findings provided principles for the design of new nickel catalyzed reactions. Future reports will include results on multi-kilo scale using this methodology and efforts towards achieving the intermolecular version of this transformation.

\section{Acknowledgements}

We thank the Boehringer-Ingelheim-Pfizer-Glaxo-SmithKlineAbbvie Non-Precious Metal Catalysis Consortium for general discussions in this area. 3D structures of Fig. 2 were generated using CYLview. ${ }^{30}$ We thank the National Institutes of Health (GM087605 to M. C. K.) for financial support. Computational support was provided by XSEDE on SDSC Gordon (TGCHE120052).

\section{Notes and references}

1 For reviews on direct arylation of (hetero)arenes, see: (a) L. Ackermann, R. Vicente and A. R. Kapdi, Angew. Chem., Int. Ed., 2009, 48, 9792-9826; (b) D. Alberico, M. E. Scott and M. Lautens, Chem. Rev., 2007, 107, 174-238; (c) J. Roger, A. L. Gottumukkala and H. Doucet, ChemCatChem, 2010, 2, 20-40; (d) R. Rossi, F. Bellina, M. Lessi and C. Manzini, Adv. Synth. Catal., 2014, 356, 17117.

2 (a) J. A. Bull, J. J. Mousseau, G. Pelletier and A. B. Charette, Chem. Rev., 2012, 112, 2642-2713; (b) L.-C. Campeau and K. Fagnou, Chem. Soc. Rev., 2007, 36, 1058-1068.

3 (a) S. Z. Tasker, E. A. Standley and T. F. Jamison, Nature, 2014, 299-309; (b) Modern Organonickel Chemistry, ed. Y.
Tamaru, Wiley-VCH, Weinheim, 2005; (c) B. M. Rosen, K. W. Quasdorf, D. A. Wilson, N. Zhang, A.-M. Resmerita, N. K. Garg and V. Percec, Chem. Rev., 2011, 111, 1346-1416. 4 Non-Precious Metal Consortium established in 2012 (see Acknowledgements section).

5 (a) K. J. Stauffer, P. D. Williams, H. G. Selnick, P. G. Nantermet, C. L. Newton, C. F. Homnick, M. M. Zrada, S. D. Lewis, B. J. Lucas, J. A. Krueger, B. L. Pietrak, E. A. Lyle, R. Singh, C. Miller-Stein, R. B. White, B. Wong, A. A. Wallace, G. R. Sitko, J. J. Cook, M. A. Holahan, M. Stranieri-Michener, Y. M. Leonard, J. J. Lynch Jr, D. R. McMasters and Y. Yan, J. Med. Chem., 2005, 48, 2282-2293; (b) B. E. Evans, K. F. Gilbert, J. M. Hoffman and K. E. Rittle, GB2355457, 2000; (c) A. L. Salzman, WO2007/117289, 2007; (d) C. Hamblett, S. Kattar, D. Mampreian, J. Method, T. Miller and P. Tempest, WO2007/136605, 2007; (e) N. S. Prostakov, A. T. Soldatenkov, V. O. Fedorov, V. M. Bagdadi and M. M. Borisov, Pharm. Chem. J., 1987, 21, 408-411.

6 (a) N. S. Prostakov, A. T. Soldatenkov, V. O. Fedorov, S. Mobio and M. A. Galiullin Chem, Heterocycl. Compd., 1980, 16, 1149-1153; (b) D. G. Krotko, K. V. Fedotov and A. I. Tolmachev, Dyes Pigm., 2005, 65, 183-189.

7 (a) Y. G. Kim, Y. J. Cho, H. J. Kwon, B. O. Kim, S. M. Kim and S. S. Yoon, WO2010/114266, 2010; (b) T. Takasu, R. Nomura, S. Shitagaki and S. Seo, WO2009/119869, 2009.

8 L. Garrido, E. Zubia, M. J. Ortega and J. Salva, J. Org. Chem., 2003, 68, 293.

9 (a) N. S. Prostakov, A. A. Obynochnyi, N. M. Kolyadina and A. T. Soldatenkov, Russ. Chem. Rev., 1997, 66, 121-138; (b) N. S. Prostakov, Russ. Chem. Rev., 1969, 38, 774-782; (c) G. A. Urbina, Synth. Commun., 1979, 9, 245-250; (d) C. Mayor and C. Wentrup, J. Am. Chem. Soc., 1975, 97, 7467-7480.

10 For a review on nickel-catalyzed $\mathrm{C}-\mathrm{H}$ bond functionalization reactions, see: X.-H. Cai and B. Xie, ARKIVOC, 2015, 184-211. 11 (a) M. Tobisu, I. Hyodo and N. Chatani, J. Am. Chem. Soc., 2009, 131, 12070-12071; (b) I. Hyodo, M. Tobisu and N. Chatani, Chem.-Asian J., 2012, 7, 1357-1365.

12 (a) T. J. A. Graham, J. D. Shields and A. G. Doyle, Chem. Sci., 2011, 2, 980-984; (b) J. D. Shields, D. T. Ahneman, T. J. A. Graham and A. G. Doyle, Org. Lett., 2014, 16, 142145; (c) K. T. Sylvester, K. Wu and A. G. Doyle, J. Am. Chem. Soc., 2012, 134, 16967-16970.

13 S. T. Chau, J. P. Lutz, K. Wu and A. G. Doyle, Angew. Chem., Int. Ed., 2013, 52, 9153-9156.

14 For palladium-catalyzed C-3 inter-molecular arylations of pyridine derivatives, see: (a) P. Guo, J. M. Joo, S. Rakshit and D. Sames, J. Am. Chem. Soc., 2011, 133, 16338-16341; (b) M. Wasa, B. T. Worrell and J.-Q. Yu, Angew. Chem., Int. Ed., 2010, 49, 1275-1277; (c) M. Ye, G.-L. Gao, A. J. F. Edmunds, P. A. Worthington, J. A. Morris and J.-Q. Yu, J. Am. Chem. Soc., 2011, 133, 19090-19093; (d) G. L. Gao, W. Xia, P. Jain and J.-Q. Yu, Org. Lett., 2016, 18, 744-747.

15 For examples of palladium-catalyzed C-3 intra-molecular direct arylations of pyridine derivatives, see: (a) 
S. K. Singh, A. L. Ruchelman, T.-K. Li, A. Liu, L. F. Liu and E. J. LaVoie, J. Med. Chem., 2003, 46, 2254-2257; (b) C. Meyers, G. Rombouts, K. T. J. Loones, A. Coelho and B. U. W. Maes, Adv. Synth. Catal., 2008, 350, 465-470.

16 For nickel-catalyzed alkyne insertion into pyridines, see $(a)$ C.-C. Tsai, W.-C. Shih, C.-H. Fang, C.-Y. Li, T.-G. Ong and G. P. A. Yap, J. Am. Chem. Soc., 2010, 132, 11887-11889; (b) Y. Nakao, Y. Yamada, N. Kashihara and T. Hiyama, J. Am. Chem. Soc., 2010, 132, 13666-13668; (c) Y. Nakao, K. S. Kanyiva and T. Hiyama, J. Am. Chem. Soc., 2008, 130, 2448-2449.

17 (a) J. D. Shields, E. E. Gray and A. G. Doyle, Org. Lett., 2015, 17, 2166-2169; (b) J. Magano and S. Monfette, ACS Catal., 2015, 5, 3120-3123.

18 All calculations were carried out using Gaussian09, see: M. J. Frisch, et al., Gaussian09, Revision A. 02, Gaussian, Inc., Wallingford, CT, 2004, see ESI $\uparrow$ for full reference and computational details.

19 For examples of mechanistic/DFT studies on nickelcatalyzed systems, see: (a) G. D. Jones, J. L. Martin, C. McFarland, O. R. Allen, R. E. Hall, A. D. Haley, R. J. Brandon, T. Konovalova, P. J. Desrochers, P. Pulay and D. A. Vicic, J. Am. Chem. Soc., 2006, 128, 13175-13183; (b) X. Lin and D. L. Phillips, J. Org. Chem., 2008, 73, 36803688; (c) B.-L. Lin, L. Liu, Y. Fu, S.-W. Luo, Q. Chen and Q.-X. Guo, Organometallics, 2004, 23, 2114-2123.

20 For a recent computational report on nickel catalysis from our group, see: O. Gutierrez, J. C. Tellis, D. N. Primer, G. A. Molander and M. C. Kozlowski, J. Am. Chem. Soc., 2015, 137, 4896-4899.

21 Similar energetics were observed when iodine-substrate (see $\mathrm{ESI} \dagger$ ).
22 (a) Y. Aihara and N. Chantani, J. Am. Chem. Soc., 2014, 136, 898-901; (b) X. Wu, Y. Zhao and H. Ge, J. Am. Chem. Soc., 2014, 136, 1789-1792; (c) X. Wu, Y. Zhao and H. Ge, J. Am. Chem. Soc., 2015, 137, 4924-4927.

23 (a) A. H. Cherney, N. T. Kadunce and S. E. Reisman, J. Am. Chem. Soc., 2013, 135, 7442-7445; (b) M. A. Prasad and M. V. Sangaranarayanan, Electrochim. Acta, 2005, 51, 242246; (c) G. A. Russell, E. G. Janzen and E. T. Strom, J. Am. Chem. Soc., 1963, 86, 1807-1814.

24 The use of 1-chloro-2,4-dinitrobenzene ( 0.5 equiv.) under optimal conditions led to a complete inhibition of product formation ( $0 \%$ yield).

25 (a) S. Biswas and D. J. Weix, J. Am. Chem. Soc., 2013, 135, 16192-16197; (b) C. Liu, S. Tang, D. Liu, J. Yuan, L. Zheng, L. Meng and A. Lei, Angew. Chem., Int. Ed., 2012, 51, 36383641 .

26 When dihydropyridine 2 (Scheme $1, \mathrm{PG}=N$-benzyl) was treated under optimal conditions, $15 \%$ yield was obtained. When 1 equivalent of $\mathrm{DBU} \cdot \mathrm{HBr}$ was used as an additive, the desired product was obtained with $77 \%$ yield. When 1 equivalent of TBAB was used, $34 \%$ was obtained.

27 M. C. Henningsen, S. Jeropoulos and E. H. Smith, J. Org. Chem., 1989, 54, 3015-3018.

28 (a) G. H. Hugar and S. T. Nandibewoor, Indian J. Chem., Sect. A, 1993, 32, 1056-1059; (b) I. Pastoriza-Santos and L. M. LisMarzan, Langmuir, 1999, 15, 948-951.

29 J. Breitenfeld, J. Ruiz, M. D. Wodrich and X. Hu, J. Am. Chem. Soc., 2013, 135, 12004-12012.

30 C. Y. Legault, CYLview, version 1.0b, Université de Sherbrooke, 2009, http://www.cylview.org. 